\title{
Pengaruh Promosi Ebod Jaya terhadap Loyalitas Konsumen
}

\author{
Ihsan Kurnia Utama \\ Program Studi Magister Ilmu Komunikasi Pascasarjana Universitas Islam Bandung \\ e-mail:sanbokz@gmail.com
}

\begin{abstract}
The strict competition urges the company to be more innovative and creative in selecting a strategy to promote its products in order to secure its business position. Ebod Jaya is one of the leading manufacturers of kicaumania in Indonesia. This research was conducted to find out the extent of the influence of personal selling, advertising, word of mouth toward consumer loyalty. This research applied explanatory survey method which aims to test the hypothesis to display the states of the causal relationship between two or more variables with a small bias in order to increase the credibility. However, the results of the research showed that Ebod Jaya promotion influence significantly against repeat purchases and the variable of advertising and word of mouth, whereas personal selling does not influence significantly. On refers others only word of mouth variables that indicates the influence significantly, whereas for personal selling and advertising no significant effect were shown.
\end{abstract}

Keywords : Advertising, Personal Selling, Refers Others, Repeat Purchases, Word Of Mouth

\begin{abstract}
Abstrak. Ketatnya persaingan yang ada menuntut perusahaan untuk lebih inovatif dan kreatif dalam memilih strategi mempromosikan produk untuk mengamankan posisi bisnisnya. Ebod Jaya merupakan sebuah produsen perlengkapan kicaumania di Indonesia. Penelitian ini dilakukan untuk mengetahui seberapa besar pengaruh personal selling, advertising, word of mouth terhadap loyalitas konsumen. Penelitian ini menggunakan metode survey eksplanatori yang mempunyai tujuan untuk menguji hipotesis yang menyatakan hubungan sebab akibat antara dua variabel atau lebih dengan bias yang kecil dan meningkatkan kepercayaan. Hasil penelitian diketahui bahwa promosi Ebod Jaya berpengaruh secara signifikan terhadap repeat purchases hanya variabel advertising dan word of mouth sedangkan untuk personal selling tidak berpengaruh secara signifikan. Pada referse others yang berpengaruh secara signifikan hanya variabel word of mouth sedangkan untuk personal selling dan advertising tidak berpengaruh secara signifikan.
\end{abstract}

Kata Kunci: Advertising, Personal Selling, Refers Others, Repeat Purchases, Word Of Mouth

\section{Pendahuluan}

Promosi merupakan salah satu faktor penentu keberhasilan suatu program pemasaran. Definisi dari Promosi itu sendiri yaitu suatu bentuk media komunikasi pemasaran (Shimp, 2003:4) mendefinisikan "Komunikasi pemasaran adalah aspek penting dalam keseluruhan misi pemasaran serta penentu suksesnya pemasaran".

Perkembangan dunia usaha yang tidak lepas dari persaingan saat ini menuntut perusahaan untuk kreatif dan berinovasi agar dapat bertahan. Selain itu salah satu strategi yang tepat untuk 
bertahan dari persaingan tinggi dalam dunia usaha saat ini adalah dengan mempertahankan loyalitas pelanggannya. Loyalitas pelanggan merupakan hal yang sangat penting ditengah persaingan bisnis yang tinggi, karena dengan loyalitas akan bermanfaat bagi perkembangan jangka panjang perusahaan. menurut (Kotler \& Keller, 2006: 153) menciptakan hubungan yang kuat dan erat dengan pelanggan adalah mimpi semua pemasar dan hal ini sering menjadi kunci keberhasilan pemasaran jangka panjang.

Perkembangan kicau mania di Indonesia cukup melesat tinggi. Terbukti banyaknya minat masyarakat dalam memelihara burung kicau yang tidak ada habisnya serta banyaknya event perlombaan yang diselenggarakan di kota kota besar setiap bulannya ataupun acara tahunan yang sudah menjadi rutinitasnya. Di daerah Jawa Barat sendiri khususnya kota Bandung tempat perlombaan cukup banyak.

Hobi burung kicauan membawa dampak sosial-ekonomi positif di berbagai kota di Jawa, Bali, Sumatera, dan Kalimantan. Bahkan dalam survei Burung Indonesia pada tahun 2006, hobi burung kicauan memiliki kontribusi minimal $\mathrm{Rp} 754$ miliar / tahun, hanya di enam kota terbesar di Jawa dan Bali (Jakarta, Bandung, Jogja, Semarang, Surabaya, Denpasar). Uang sebesar itu berputar ke sana-kemari, bahkan mampu menghidupi ribuan kepala rumah tangga melalui bisnis pakan burung, berdagang burung, penangkaran burung, perajin sangkar dan aksesoris kandang. Bukan hanya itu, hobi burung kicauan terbukti juga dapat menyatukan warga Indonesia dengan kelas sosial dan etnis yang berbeda, untuk datang bersama-sama dalam kepentingan yang sama pula, yaitu lomba burung, setiap pekan. ${ }^{1}$

Diawali pada tahun 1994 bapak Makfud memulai bisnisnya sebagai produsen perlengkapan kicau mania dengan diberi nama Ebod Jaya. Hingga saat ini berbagai macam produk telah diproduksi Ebod Jaya mulai dari perlengkapan sangkar, pakan burung, hingga vitamin burung. Telah 20 tahun Ebod Jaya berkecimpung dalam bisnis berbagai macam perlengkapan kicaumania. Dengan lebih dari 26.000 Anggota dalam Grup Ebod Jaya Family Facebook. $^{2}$

Kesuksesan Ebod Jaya dalam bisnis perlengkapan kicau mania telah menjadikannya sebagai salah satu brand yang sangat dikenal dan tidak asing lagi bagi kicau mania di Indonesia, meskipun tidak menutup kemungkinan para kompetitor meniru kegiatan promosi atau pun produk produk Ebod Jaya seperti halnya BnR dan Oriq Jaya yang sama halnya menjadi produsen perlengkapan kicau mania yang hingga saat ini menjadi pesaing kuat dari Ebod Jaya. namun Ebod Jaya mampu menarik perhatian para kicaumania Indonesia lewat beberapa aktivitas pemasaran antara lain pada media baik dalam media cetak ataupun online, penyelenggaraan lomba burung berkicau dalam skala regional dan nasional, branding toko pakan burung yang berlokasi di berbagai pasar burung di Indonesia, serta sponsorship lapangan lomba independent yang dijadikan sebagai alat promosi produk.

Oleh sebab itu melihat respon yang besar dari kicau mania di Indonesia terutama dalam perlombaan burung di kota Bandung yang

\footnotetext{
${ }^{1}$ http://omkicau.com/sejak-kapan-lomba-burungkicauan-digelar-di-Indonesia Diakses pada 17 Februari 2016 Pukul 11:00WIB

${ }^{2}$ https://www.facebook.com/groups/ebodjaya.fa mily Diakses pada 23 Desember 2015 Pukul 14:00WIB
} 
diselenggarakan oleh Ebod Jaya maupun bekerjasama dengan pihak lain, maka penulis merasa tertarik untuk meneliti seberapa besar pengaruh Promosi terhadap Loyalitas konsumen.

\section{Metode}

Penelitian ini mempergunakan metode studi eksplanatori adalah "Suatu penelitian yang mempunyai tujuan untuk menguji hipotesis yang menyatakan hubungan sebab akibat antara dua variabel atau lebih dengan bias yang kecil dan meningkatkan kepercayaan" (Soehartono, 2000:33). Penelitian ini diarahkan pada pengungkapan hubungan kausal antara variabel yang diteliti, yakni menyelidiki hubungan sebab berdasarkan pengamatan terhadap akibat yang terjadi, sehingga pengaruh langsung dan pengaruh tidak langsung variabel penyebab terhadap variabel akibat dapat dipisahkan.

Variabel yang diteliti adalah Pengaruh Promosi (X) terhadap Loyalitas Konsumen (Y) pada Produk Ebod Jaya. Menurut (Riduwan \& Kuncoro, 2007:209), penelitian survei yang bersifat eksplanatori menuntut adanya ketelitian, ketekunan, dan sikap kritis dalam menjaring data dari sumbernya, sehingga diperlukan kejelasan sumber data, yaitu populasi dan sampel dari sisi homogenitas, volume dan sebarannya.

\section{Temuan dan Pembahasan}

Berdasarkan pengujian sub-sub struktur yang telah dilakukan, maka aspek-aspek penting yang dapat dikemukakan adalah sebagai berikut:

Pada Substruktur 1, Promosi Ebod Jaya yang meliputi personal selling, advertising dan word of mouth berpengaruh secara signifikan terhadap repeat purchases yaitu sebesar $41.7 \%$. Berdasarkan hasil pengujian koefisien jalur substruktur 1 diketahui bahwa 2 subvariabel dari promosi yaitu advertising dan word of mouth berpengaruh secara signifikan terhadap repeat purchases. Tetapi subvariabel personal selling tidak berpengaruh secara signifikan terhadap repeat purchases.

Dari hasil penelitian pengaruh personal selling terhadap repeat purchases tidak signifikan, hal ini disebabkan oleh beberapa faktor. Diketahui bahwa wiraniaga Ebod Jaya rata-rata berpendidikan SMA/sederajat, sehingga mereka kurang dapat memberikan informasi yang jelas, mendidik dan mempersuasi konsumen untuk membeli produk Ebod Jaya, karena Ebod Jaya kurang memberikan pembekalan / pengarahan mengenai macam macam informasi produk Ebod Jaya. Selain itu responden mayoritas berpendidikan SMA/sederajat sehingga mungkin mereka kurang dapat menangkap berbagai macam informasi yang disampaikan oleh wiraniaga.

Dari hasil penelitian, advertising berpengaruh secara signifikan terhadap repeat purchases, artinya segala kegiatan advertising yang dilakukan Ebod Jaya mulai dari Internet, majalah, spanduk, flyer, billboard serta umbulumbul berhasil memperngaruhi konsumen untuk membeli ulang produk Ebod Jaya.

Dari hasil penelitian word of mouth berpengaruh secara signifikan terhadap repeat purchases, ini artinya produk Ebod Jaya yang dibicarakan oleh konsumen dari mulut ke mulut kepada konsumen atau calon konsumen lain untuk mempengaruhi konsumen atau calon konsumen tersebut agar membeli kembali produk Ebod Jaya. Konsumen atau Calon Konsumen akan lebih terpengaruh untuk membeli kembali produk ketika dia mendengar langsung pengalaman seseorang yang telah menggunakan produk tersebut 
sebagai contohnya salah satu burung milik seseorang mampu menjadi juara pada event perlombaan yang disebabkan oleh penggunaan pakan burung yang di produksi oleh Ebod Jaya hal ini akan mempengaruhi kontestan lain untuk menggunakan pakan Ebod Jaya. Word of mouth ini biasanya terjadi pada saat event perlombaan burung berkicau berlangsung atau dapat juga pada saat aktifitas di fanpage Facebook Ebod Jaya Family, ataupun social media lainnya.

Pada Substruktur 2, Promosi Ebod Jaya yang meliputi personal selling, advertising dan word of mouth berpengaruh secara signifikan terhadap referse others yaitu sebesar $37.2 \%$. Berdasarkan hasil pengujian koefisien jalur substruktur 2 diketahui bahwa hanya subvariable dari promosi yaitu word of mouth yang berpengaruh secara signifikan terhadap repeat others. Tetapi subvariabel personal selling dan advertising tidak berpengaruh secara signifikan terhadap repeat others.

Dari hasil penelitian pengaruh personal selling terhadap refers others tidak signifikan, hal ini disebabkan oleh beberapa faktor. Diketahui bahwa wiraniaga Ebod Jaya rata-rata berpendidikan SMA/sederajat, sehingga mereka kurang dapat memberikan informasi yang jelas, mendidik dan mempersuasi konsumen. Responden pun mayoritas berpendidikan SMA/sederajat sehingga mereka kurang dapat menerima informasi yang disampaikan sehingga tidak dapat mereferensikan kembali kepada Konsumen atau Calon konsumen lain.

Dari hasil penelitian, advertising tidak berpengaruh secara signifikan terhadap refers others, artinya segala kegiatan advertising yang dilakukan Ebod Jaya mulai dari Internet, tabloid, spanduk, flyer, billboard serta umbulumbul kurang mempersuasi Konsumen untuk mereferensikan produk Ebod Jaya kepada Konsumen atau calon
Konsumen lainnya. Hal ini disebabkan oleh beberapa faktor dalam konteks advertising di internet, tidak semua kicaumania menggunakan media sosial. Untuk tabloid kalangan Remaja yang sebagian besar menjadi responden tidak membaca tabloid atau koran lagi, yang berarti kegiatan advertising yang dilakukan Ebod Jaya pada media cetak / tabloid tidak dapat menjangkau kalangan tersebut. Serta untuk Flyer biasanya jenis bahan yang digunakan mudah sobek, artinya gangguan teknis dalam flyer sangat tinggi yang mengakibatkan informasi yang diterima tidak lengkap serta orang cenderung mengabaikan informasi yang diberikan apabila bentuk flyer kurang menarik.

Dari hasil penelitian word of mouth berpengaruh secara signifikan terhadap refers others, ini artinya produk Ebod Jaya yang dibicarakan oleh konsumen dari mulut ke mulut kepada konsumen lain untuk mempengaruhi konsumen tersebut agar membeli kembali produk Ebod Jaya. Konsumen atau calon Konsumen akan lebih terpengaruh untuk membeli kembali produk ketika dia mendengar langsung pengalaman seseorang yang telah menggunakan produk tersebut sebagai contohnya salah satu burung milik seseorang mampu menjadi juara pada event perlombaan yang disebabkan oleh penggunaan pakan burung yang di produksi oleh Ebod Jaya, hal ini akan mempengaruhi kontestan lain untuk menggunakan pakan Ebod Jaya. Word of mouth ini biasanya terjadi pada saat event perlombaan burung berkicau berlangsung atau dapat juga pada saat aktifitas di fanpage Facebook Ebod Jaya Family, ataupun social media lainnya.

Selain untuk melihat bagaimana pengaruh promosi Ebod Jaya yang meliputi personal selling, advertising dan word of mouth terhadap loyalitas konsumen yang meliputi repeat purchases dan referse others, penelitian 
ini sekaligus untuk mendukung dan membuktikan teori.

Teori Behaviorisme sebagai grand theory pada penelitian ini, dalam komunikasi behaviorisme merupakan suatu perspektif yang memfokuskan respon terhadap stimulus eksternal dan internal yang berupaya mencari pola yang jelas antara stimulus dan respons. jika dikaitkan dengan promosi Ebod jaya merupakan kegiatan komunikasi pemasaran yang akan diterima oleh komunikan yang memfokuskan respon dari komunikan dalam hal ini respon tersebut berupa loyalitas konsumen.

Middle range theory pada penelitiani ini adalah Teori Stimulus Respons adalah teori komunikasi linear yang paling tua. Teori stimulus merupakan proses komunikasi yang berjalan secara satu arah. Model Komunikasi Stimulus Respons pada dasarnya merupakan suatu prinsip belajar yang sederhana, dimana efek merupakan reaksi terhadap stimulus tertentu. Dengan demikian seseorang dapat memahami kaitan antara pesan dan media dan reaksi audien. Sehingga stimulus yang berupa promosi Ebod Jaya akan di respon oleh organisme dalam hal ini adalah konsumen, dan respon tersebut berupa loyalitas konsumen.

Menurut (Aaker, 1991:255), teori respon kognitif berasumsi bahwa khalayak secara aktif terlibat dalam proses penerimaan informasi dengan cara mengevaluasi informasi yang diterima berdasarkan pengetahuan dan sikap yang dimiliki sebelumnya.. Asumsi dasar teori ini kemudian menjadi landasan dalam komunikasi pemasaran dan menerapkan berbagai strategi komunikasi pemasaran yang secara sederhana dapat dijelaskan bahwa setiap konsumen selalu mengalami reaksi kognitif ketika menerima beragam informasi dari sebuah produk yang nantinya menentukan loyalitas konsumen terhadap produk.

Ketika informasi mengubah
tingkah laku konsumen disebabkan
karena konsumen mempelajari

informasi yang diterima, yang kemudian mengarah pada perubahan tingkah laku terhadap suatu objek, produsen perlu mendesain informasi secara tepat agar konsumen dapat mempelajari informasi secara maksimal dan pada akhirnya perubahan sikap positif yang diharapkan oleh produsen dari konsumen dapat terjadi.

\section{Simpulan dan Saran}

Berdasarkan hasil temuan penelitian dan analisis hasil penelitian mengenai pengaruh promosi ebod jaya terhadap loyalitas konsumen, maka dapat ditarik simpulan, sebagai berikut:

1. Hasil hipotesis dari struktur pengaruh personal selling, advertising dan word of mouth secara bersama-sama berpengaruh secara signifikan terhadap repeat purchases, adapun pengaruh dari masingmasing sub variable dari variable promosi adalah sebagai berikut:

a. Personal selling secara signifikan tidak berpengaruh terhadap repeat purchases. hal ini disebabkan bahwa wiraniaga Ebod Jaya ratarata berpendidikan SMA/sederajat, serta Ebod Jaya kurang memberikan pembekalan / pengarahan terhadap wiraniaga mengenai macam macam informasi produk.

b. Advertising secara signifikan berpengaruh terhadap repeat purchases.

c. artinya segala kegiatan advertising yang dilakukan Ebod Jaya mulai dari 
Internet, majalah, spanduk, flyer, billboard serta umbulumbul berhasil memperngaruhi konsumen untuk membeli ulang produk Ebod Jaya.

d. Word of mouth secara signifikan berpengaruh terhadap repeat purchases. artinya produk Ebod Jaya yang dibicarakan oleh konsumen dari mulut ke mulut kepada konsumen lain mempengaruhi konsumen tersebut untuk merefensikan kembali produk Ebod Jaya kepada Konsumen lainnya. Konsumen akan lebih terpengaruh untuk mereferensikan kembali produk ketika mendengar langsung pengalaman seseorang yang telah menggunakan produk tersebut.

2. Hasil hipotesis dari struktur pengaruh personal selling, advertising dan word of mouth secara bersama-sama berpengaruh secara signifikan terhadap refers others, yaitu:

a. Personal selling secara signifikan tidak berpengaruh terhadap refers others. hal ini disebabkan wiraniaga Ebod Jaya yang berpendidikan

SMA/sederajat, serta kurang memberikan pembekalan / pengarahan terhadap wiraniaga mengenai macam macam informasi produk.

b. Advertising secara signifikan tidak berpengaruh terhadap refers others artinya segala kegiatan advertising yang dilakukan Ebod Jaya mulai dari Internet, majalah, spanduk, flyer, billboard serta umbul-umbul kurang mempersuasi Konsumen untuk mereferensikan produk Ebod Jaya kepada Konsumen atau Calon Konsumen lainnya.

c. Word of mouth secara signifikan berpengaruh terhadap refers others artinya produk Ebod Jaya yang dibicarakan oleh konsumen dari mulut ke mulut kepada konsumen lain mempengaruhi konsumen tersebut untuk merefensikan kembali produk Ebod Jaya kepada Konsumen lainnya.

Berdasarkan penelitian yang dilakukan, peneliti mengajukan saransaran sebagai berikut:

1. Ebod Jaya perlu memperbaiki kegiatan personal selling dengan memberikan pelatihan kepada wiraniaga mengenai informasi produk Ebod Jaya, strategi promosi, serta penguasaan mengenai perusahaan. Melalui pelatihan diharapkan wiraniaga dapat lebih memahami apa yang akan mereka sampaikan kepada konsumen sehingga konsumen dapat lebih memahami dan terpersuasi untuk melakukan pembelian kembali dan menyampaikan kembali informasi yang didapatkan kepada orang lain.

2. Ebod Jaya harus merubah gaya iklan dengan lebih memperhatikan konten informasi pada iklan. Konten informasi harus lebih akurat, tepat waktu, relevan dan lengkap sehingga tidak timbul bias komunikasi dan menghasilkan informasi yang berkualitas.

3. Ebod Jaya harus memperhatikan serta meningkatkan aspek informasi baik mengenai produk 


\begin{abstract}
ataupun perusahaan yang diberikan kepada konsumen, karena word of mouth dapat menjadi metode promosi efektif yang pada umumnya disampaikan dari konsumen oleh konsumen dan untuk konsumen, sehingga konsumen yang puas akan informasi yang diterima dari Ebod Jaya dapat menjadi media iklan bagi Ebod Jaya itu sendiri.
\end{abstract}

\title{
Daftar Pustaka
}

Aaker David, 1991. Manajemen Ekuitas Merek. Jakarta: Spektrum Mitra Utama.

Kotler, Philip, Kevin Lane Keller. 2006. Marketing Management. Pearson Education Inc.

Riduwan dan Kuncoro, Engkos Achmad. 2007. Cara Menggunakan dan Memaknai Analisis Jalur (Path Analysis. Bandung: Alfabeta.

Shimp, Terence A. 2003. Periklanan dan Promosi. Jakarta: Erlangga

Website

https://www.facebook.com/groups/ebod jaya.family diakses pada 23 Desember 2015 Pukul 14:00 WIB. http://omkicau.com diakses pada 17 Februari 2016 Pukul 11:00 WIB 